\title{
GZD824 suppresses the growth of human B cell precursor acute lymphoblastic leukemia cells by inhibiting the SRC kinase and PI3K/AKT pathways
}

\author{
Wei Ye $^{1,2,3,4, *}$, Zhiwu Jiang ${ }^{2,3,4, *}$, Xiaoyun Lu ${ }^{2}$, Xiaomei Ren ${ }^{2}$, Manman Deng ${ }^{5}$, \\ Shouheng $\operatorname{Lin}^{2,3,4}$, Yiren $\mathrm{Xiao}^{2,3,4}$, Simiao Lin ${ }^{2,3,4}$, Suna Wang ${ }^{2,3,4}$, Baiheng $\mathrm{Li}^{2,3,4}$, \\ Yi Zheng ${ }^{2,3,4}$, Peilong Lai ${ }^{6}$, Jianyu Weng ${ }^{6}$, Donghai Wu ${ }^{3,4}$, Yuguo Ma ${ }^{7}$, Xudong Chen ${ }^{8}$, \\ Zhesheng Wen ${ }^{9}$, Yaoyu Chen ${ }^{10}$, Xiaoyan Feng ${ }^{11}$, Yangqiu Li ${ }^{12,13}$, Pentao Liu ${ }^{14}$, Xin \\ $\mathrm{Du}^{6}$, Duanqing $\mathrm{Pei}^{3,4}$, Yao $\mathrm{Yao}^{15}$, Bing $\mathrm{Xu}^{5}$, Ke Ding ${ }^{2}$ and Peng $\mathbf{L i}^{2,3,4}$ \\ ${ }^{1}$ School of Life Science, University of Science and Technology of China, Anhui, China \\ ${ }^{2}$ State Key Laboratory of Respiratory Disease, Guangzhou Institutes of Biomedicine and Health, Chinese Academy of \\ Sciences, Guangzhou, China \\ ${ }^{3}$ Key Laboratory of Regenerative Biology, South China Institute for Stem Cell Biology and Regenerative Medicine, Guangzhou \\ Institutes of Biomedicine and Health, Chinese Academy of Sciences, Guangzhou, China \\ ${ }^{4}$ Guangdong Provincial Key Laboratory of Stem Cell and Regenerative Medicine, South China Institute for Stem Cell Biology and \\ Regenerative Medicine, Guangzhou Institutes of Biomedicine and Health, Chinese Academy of Sciences, Guangzhou, China \\ ${ }^{5}$ Department of Hematology, The First Affiliated Hospital of Xiamen University, Xiamen, China \\ ${ }^{6}$ Department of Hematology, Guangdong Provincial People's Hospital, Guangzhou, China \\ ${ }^{7}$ Yikang Tailai Technology Co. Ltd, Guangzhou, China \\ ${ }^{8}$ Department of Interventional Radiology, Shenzhen People's Hospital, Shenzhen, China \\ ${ }^{9}$ Department of Thoracic Oncology, Sun Yat-Sen University Cancer Center, Guangzhou, China \\ ${ }^{10}$ First Affiliated Hospital of Nanjing Medical University, Jiangsu Province Hospital, Nanjing, China \\ ${ }^{11}$ Chongqing HiChuang Biomedical Corp., Chongqing, China \\ ${ }^{12}$ Department of Hematology, Medical College, Jinan University, Guangzhou, China \\ ${ }^{13}$ Key Laboratory for Regenerative Medicine of Ministry of Education, Jinan University, Guangzhou, China \\ ${ }^{14}$ Wellcome Trust Sanger Institute, Hinxton, Cambridge CB10 $1 \mathrm{HH}$, England, UK \\ ${ }^{15}$ Drug Discovery Pipeline, Guangzhou Institutes of Biomedicine and Health, Chinese Academy of Sciences, Guangzhou, China \\ "Indicates co-first authorship \\ Correspondence to: Peng Li, email: li_peng@gibh.ac.cn \\ Ke Ding, email: ding_ke@gibh.ac.cn
}

Keywords: pre-B ALL, GZD824, SRC, PI3K/AKT, PDX

Received: January 27, $2016 \quad$ Accepted: June 09, $2016 \quad$ Published: July 28, 2016

Copyright: Ye et al. This is an open-access article distributed under the terms of the Creative Commons Attribution License 3.0 (CC BY 3.0), which permits unrestricted use, distribution, and reproduction in any medium, provided the original author and source are credited.

\section{ABSTRACT}

Available therapeutic options for advanced B cell precursor acute lymphoblastic leukemia (pre-B ALL) are limited. Many lead to neutropenia, leaving patients at risk of life-threatening infections and result in bad outcomes. New treatment options are needed to improve overall survival. We previously showed that GZD824, a novel BCR-ABL tyrosine kinase inhibitor, has anti-tumor activity in Philadelphia chromosome-positive $(\mathrm{Ph}+)$ chronic myeloid leukemia cells and tumor models. Here, we show that GZD824 decreases cell viability, induces cell-cycle arrest, and causes apoptosis in pre-B ALL cells. Furthermore, Ph- pre-B ALL cells were more sensitive to GZD824 than Ph+ pre-B ALL cells. GZD824 consistently reduced tumor loads in Ph- pre-B ALL xenografts but failed to suppress Ph+ pre-B ALL xenografts. GZD824 decreased phosphorylation of SRC kinase, 
STAT3, RB and C-myc. It also downregulated the expression of $B C L-X L, C C N D 1$ and $C D K 4$ and upregulated expression of CCKN1A. Expression of IRS1 was decreased in GZD824treated pre-B ALL cells, blocking the PI3K/AKT pathway. These data demonstrate that GZD824 suppresses pre-B ALL cells through inhibition of the SRC kinase and PI3K/AKT pathways and may be a potential therapeutic agent for the management of pre-B ALL.

\section{INTRODUCTION}

Pre-B ALL is characterized by malignant proliferation and accumulation of early B lymphoid precursors in the bone marrow (BM), blood, and lymphoid organs [1] due to acquired mutations in early B cells $[2,3]$. Although pre-B ALL is highly responsive to chemotherapy, relapse occurs in approximately $25 \%$ of children [4]. The relatively non-specific actions of anti-cancer drugs often result in unacceptable toxicities that can occasionally prove fatal or produce lifelong consequences for survivors [5]. The inability to further intensify current treatments in high-risk patients due to dose-limiting toxicities means that new agents are needed to significantly improve overall survival.

The SRC non-receptor tyrosine kinase is overexpressed and activated in a large number of human malignancies, including ALL [6, 7]. Dysregulation of SRC activity rather than its overexpression is thought to be the key contributor to oncogenesis [8]. Consistent with SRC kinase, the members of the PI3K/AKT pathway are dysregulated in a wide spectrum of human cancers, including leukemia $[9,10]$. PI3K inhibitors such as BEZ235 suppress cell proliferation, induce cell death, and extend survival of NOD/SCID mice engrafted with human ALL cells [11]. These findings suggest that inhibition of the SRC kinase or PI3K/AKT pathways in ALL could be an effective new treatment for this disease.

The tyrosine kinase inhibitors (TKI) imatinib (IM), nilotinib, and dasatinib are currently used to treat adult patients with $\mathrm{Ph}+\mathrm{ALL}$ and myelodysplastic/ myeloproliferative diseases [6]. GZD824, a hybrid molecule of the FDA-approved drugs IM, nilotinib, and dasatinib, has been shown to inhibit the growth of human CML in a xenograft model $[12,13]$. The effects of GZD824 on other cancers, including pre-B ALL, have not been evaluated. Here, the efficacy of GZD824, a BCRABL TKI, was examined in pre-B ALL cell lines and adult patient primary cells.

\section{RESULTS}

\section{GZD824 has antitumor activity in human pre-B ALL cells}

We previously reported that GZD824, synthesized by hybridizing the structural moieties from the FDA-approved drugs IM, nilotinib, and dasatinib, is capable of inhibiting $\mathrm{BCR} / \mathrm{ABL}$ kinase and eliminating $\mathrm{Ph}+\mathrm{CML}$ cells [13]. We thus assessed the antitumor activity of GZD824 in
$\mathrm{Ph}+$ pre-B ALL cells. Surprisingly, we found that GZD824 inhibited the proliferation of the Ph- pre-B ALL cell line (NALM6) with an $\mathrm{IC}_{50}$ of $500 \mathrm{nM}$, much lower than that in the $\mathrm{Ph}+$ pre-B ALL cell line (SUPB15) (Figure 1A). We next investigated whether GZD824 could induce apoptosis in NALM6 or SUPB1 5 cells. Consistently, $24 \mathrm{~h}$ post drug treatment, the apoptotic rates of the NALM6 and SUPB15 cell lines were moderate with GZD824 treatment $(1 \mu \mathrm{M})$. With $3 \mu \mathrm{M}$ GZD824 treatment, $74.4 \%$ of the NALM6 cells were undergoing apoptosis $($ AnnexinV+), compared to only $48.3 \%$ of SUPB15 cells (Figure 1B). Application of $500 \mathrm{nM}$ of GZD824 did not increase the percentages of apoptotic NALM6 cells (Supplementary Figure S1A). To test the effects of GZD824 on the cell cycle of pre-B ALL cells, NALM6 and SUPB15 cells were treated with $500 \mathrm{nM}$ or $3 \mu \mathrm{M}$ GZD824. $3 \mu \mathrm{M}$ GZD824 treatment increased the proportions of the $G_{0} / G_{1}$ fraction in these two cell lines and the percentage of the $\mathrm{G}_{0} / \mathrm{G}_{1}$ fraction in NALM6 was $71.6 \%$, significantly higher than that in SUPB15 (52.2\%) (Figure 1C). Moreover, $500 \mathrm{nM}$ GZD824 increased the proportions of the $G_{0} / G_{1}$ fraction in NALM6 cells but not in SUPB15 cells (Supplementary Figure S1B). These results demonstrate that GZD824 prevents proliferation and induces apoptosis in both NALM6 and SUPB15 pre-B ALL cell lines. Furthermore, the antitumor activity of GZD824 was more effective for NALM6 than for SUPB15.

We next characterized the effects of GZD824 on primary pre-B ALL cells from five patients (Supplementary Table S1). Pre-B ALL cells from patient \#1 (P\#1), patient $\# 2$ (P\#2), and patient \#3 (P\#3) were Ph-, whereas those from patient \#4 (P\#4) and patient \#5 (P\#5) were $\mathrm{Ph}+$. GZD824 treatment significantly increased the percentages of apoptotic cells in all five samples (Figure 2A). Consistent with the results obtained from NALM6 and SUPB15, the percentages of apoptotic cells in Ph- primary pre-B ALL cells were higher than those in $\mathrm{Ph}+$ primary pre-B ALL cells upon GZD824 treatment (Figure 2A). However, GZD824 treatment did not induce apoptosis in normal human primary B cells (Figure 2B). Taken together, these results show that GZD824 specifically killed primary human pre-B ALL cells in vitro, independent of the presence of the Philadelphia chromosome.

\section{GZD824 inhibits the growth of pre-B ALL cells in patient-derived xenograft (PDX) mouse models}

To evaluate the anti-pre-B ALL activity of GZD824 in vivo, we generated human pre-B ALL PDX models by transplanting splenic pre-B ALL cells from the five 


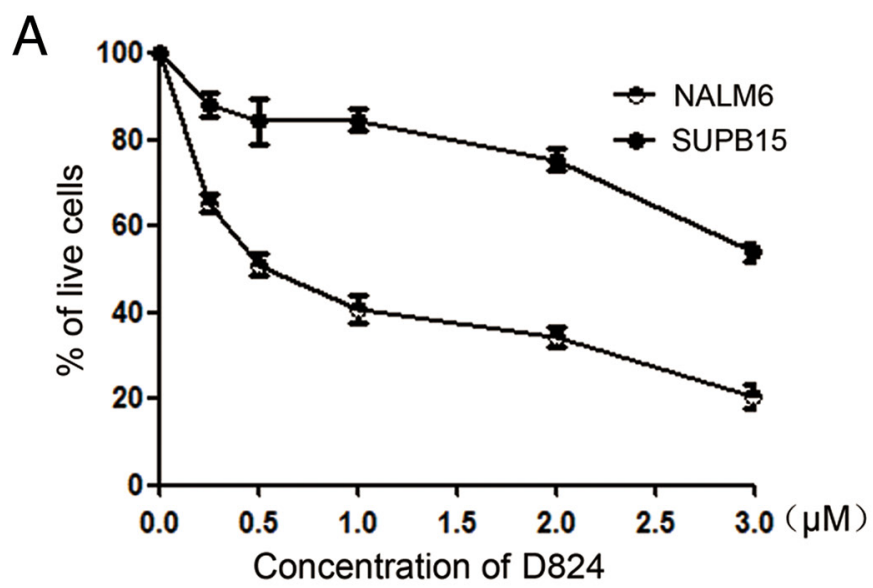

B
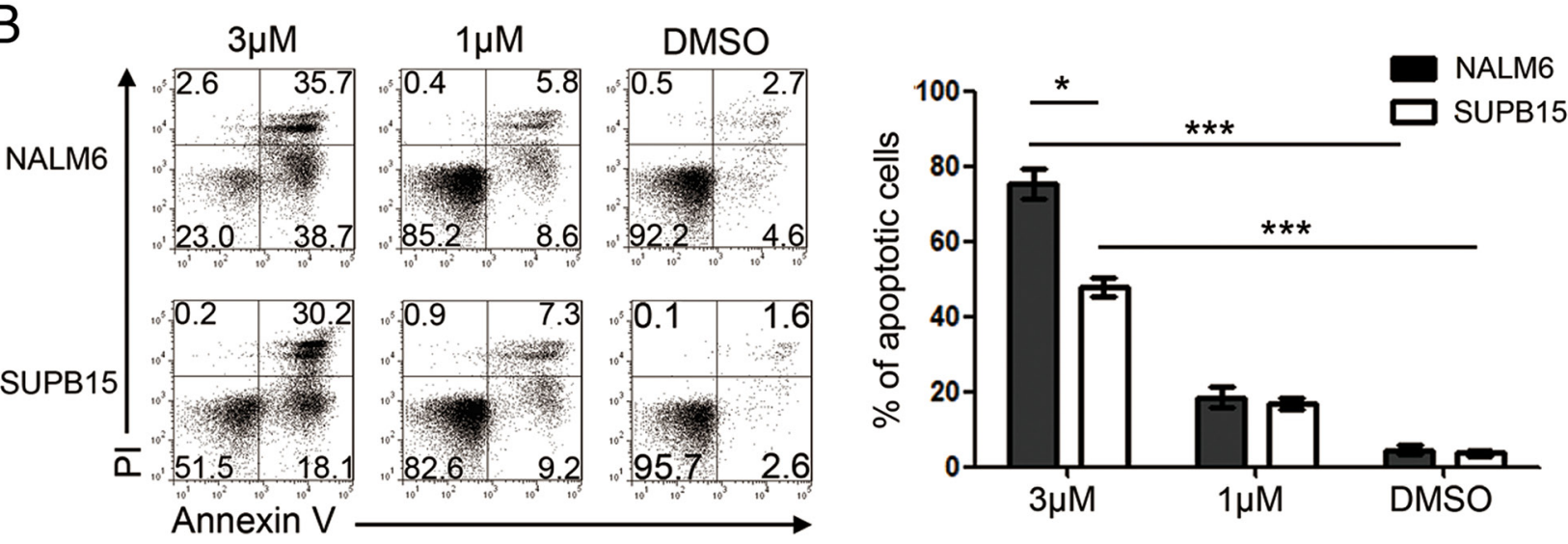

C
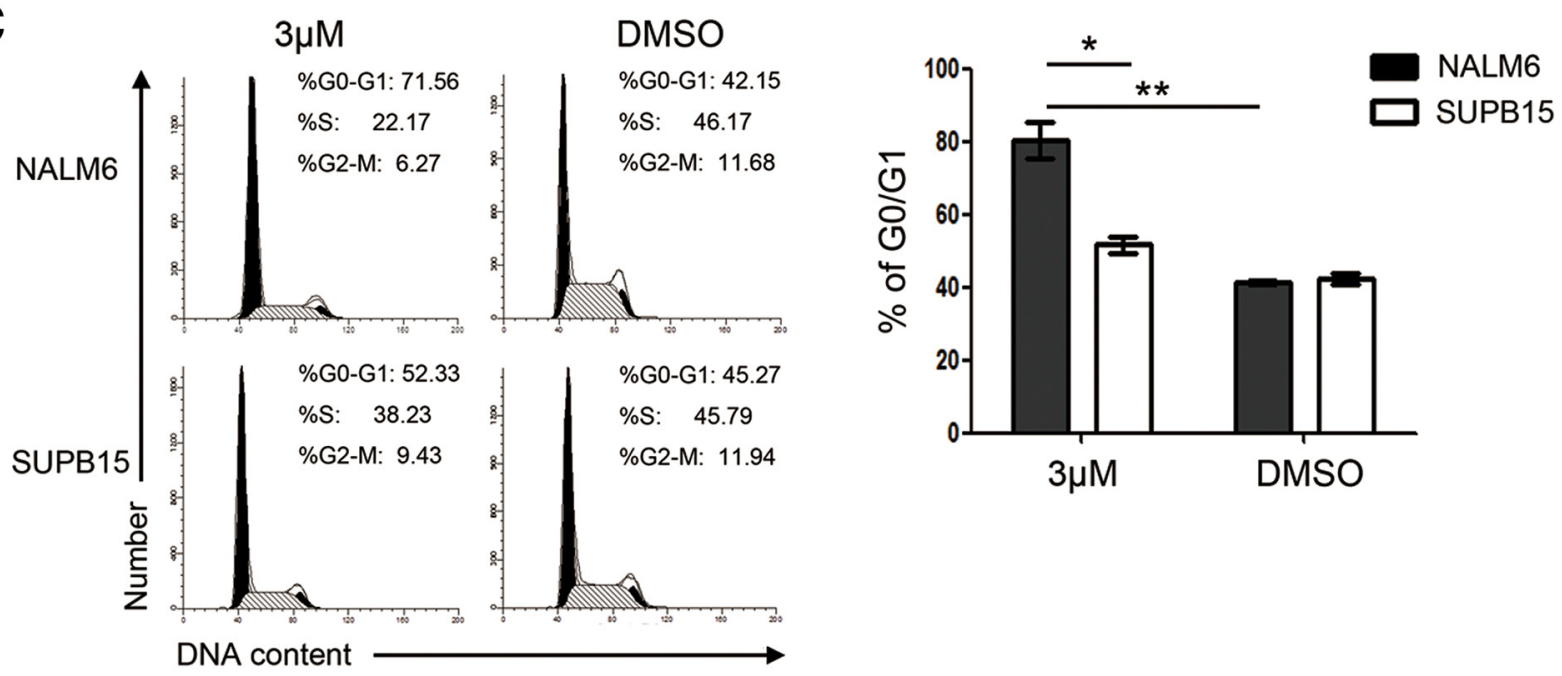

Figure 1: GZD824 inhibits proliferation and induces apoptosis and G0/G1 cell-cycle arrest of human B acute lymphoblast leukemia (pre-B ALL) cell lines. A. GZD824 cytotoxicity in pre-B ALL cells: NALM6 and SUPB15 were incubated with GZD824 at various concentrations for 24 hours, and viability was determined by CCK 8 assay. Viability was calculated relative to time-matched untreated controls. D824 is short for GZD824 in the following figure. B. Left: representative flow cytometric analysis of NALM6 and SUPB15 cells treated with DMSO, $1 \mu \mathrm{M}$, or $3 \mu \mathrm{M}$ of GZD824 for 24 hours. Right: Statistical analysis of AnnexinV-positive cells in GZD824 treated NALM6 and SUPB15 cells. C. Left: representative images of cell cycle distribution in NALM6 and SUPB15 cells treated with DMSO or $3 \mu \mathrm{M}$ of GZD824 for 24 hours. Right: Statistical analysis of the distribution of cells in G0/G1 phases in GZD824 treated cells. Data are shown as the mean \pm SEM (error bars) from three independent experiments. Significance values: ${ }^{*} \mathrm{P}<0.05 ;{ }^{* *} \mathrm{P}<0.01$; ${ }^{* * *} \mathrm{P}<0.001$. 

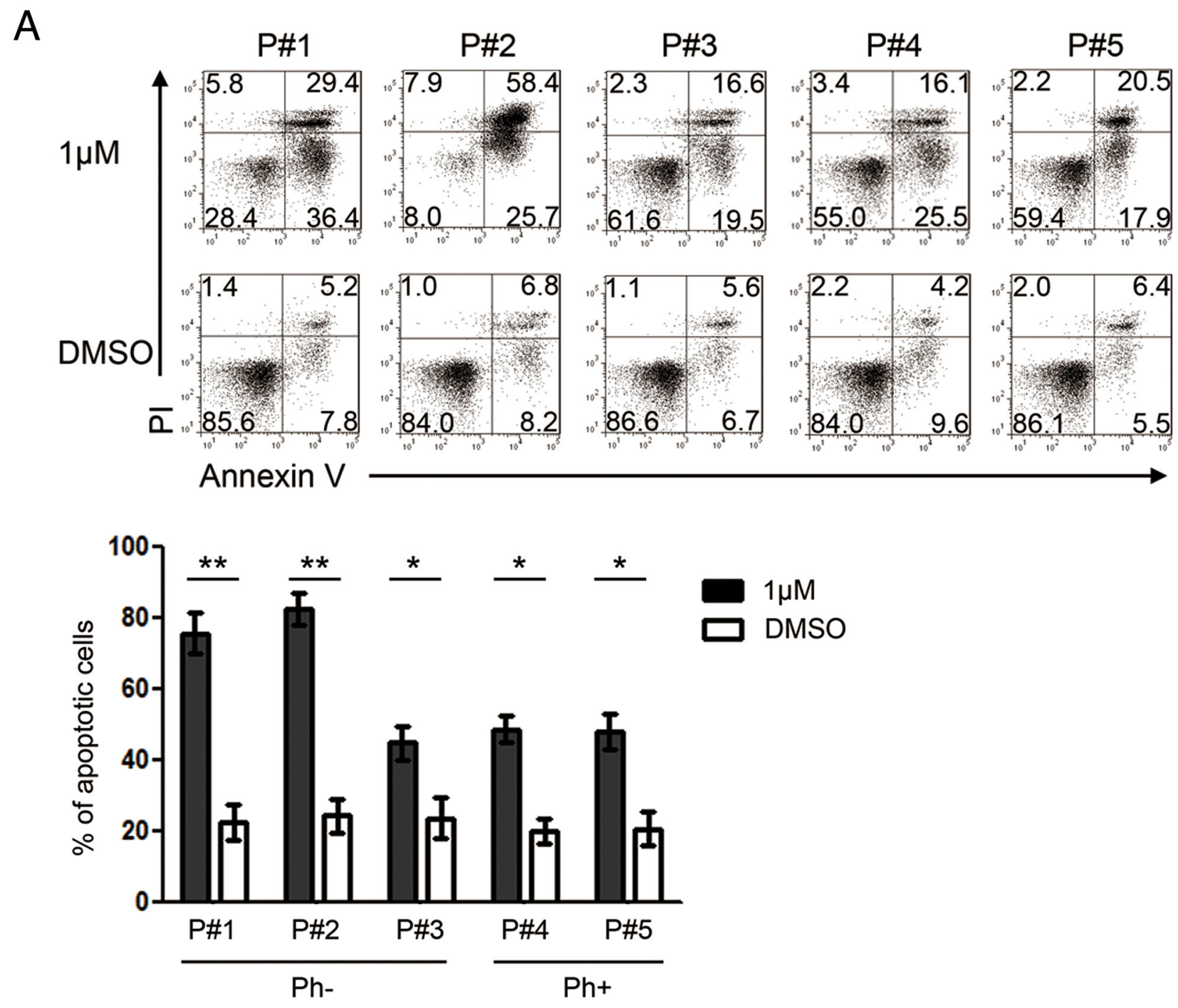

B
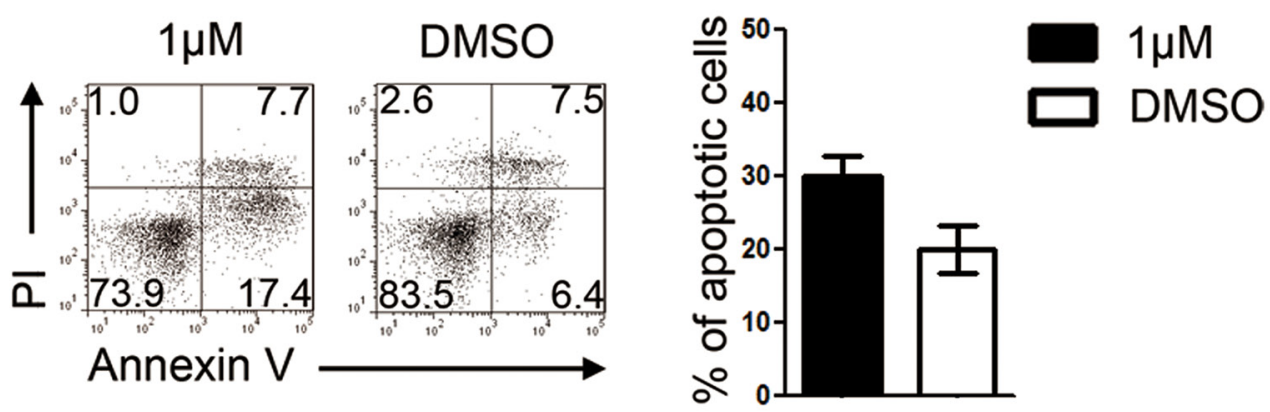

Figure 2: GZD824 induces apoptosis of primary pre-B ALL cells from patients with no toxicity to normal B cells. A. GZD824 cytotoxicity in primary pre-B ALL cells: primary pre-B ALL cells of $\mathrm{P} \# 1, \mathrm{P} \# 2$, and $\mathrm{P} \# 3$ were from Ph- pre-B ALL, and primary pre-B ALL cells of $\mathrm{P} \# 4$ and $\mathrm{P} \# 5$ were from $\mathrm{Ph}+$ pre-B ALL. Up: Representative flow cytometric analysis of primary pre-B ALL cells treated with DMSO or 1 $\mu \mathrm{M}$ GZD824. Bottom: Statistical analysis of Annexin V-positive cells in GZD824 treated primary pre-B ALL cells. (P\#1, $\mathrm{P} \# 2$, P\#3, P\#4 and P\#5 are short for patient \#1, patient \#2, patient \#3, patient \#4, and patient \#5) B. Left: Representative flow cytometric analysis of normal B cells treated with DMSO or 1 $\mu$ M GZD824. Right: Statistical analysis of AnnexinV-positive cells in GZD824 treated primary B cells. Data are shown as the mean \pm SEM (error bars) from three independent experiments. Significance values: "P $<0.05$; ${ }^{* *} \mathrm{P}<0.01 ;{ }^{* * *} \mathrm{P}<0.001$. 
patient-derived (Supplementary Table S1) xenograft mouse lines into NOD-scid-IL2Rg-/- (NSI) mice [18-21]. GZD824, IM, and DMSO treatment were started when the pre-B ALL cells in the PB of the xenograft reached $1 \% \pm 0.2 \%$ of the total (Supplementary Figure S2A and Supplementary Figure S2C). IM was used as a positive control because it is a TKI used in the treatment of multiple cancers, most notably $\mathrm{Ph}+\mathrm{CML}[6,7]$. We culled the mice after 2 weeks of drug treatment and found that the weights of the SP in the mice that were injected with pre-B ALL cells of P\#1, P\#2, and P\#3 from the GZD824 group were significantly lighter than those from either the IM group or DMSO group (Figure 3A). However, there were no significant differences in SP weights among these three groups of mice with reconstitution of pre-B ALL from patients P\#4 and P\#5 (Figure 3B). Consistently, PDX mice with $\mathrm{Ph}$ - cells that received GZD824 treatment showed reduced leukemic burden in SP and BM compared with those treated with IM or DMSO (Figure 3C).

We subsequently analyzed the residual pre-B ALL cells in the PDX mice 2 weeks after treatment with GZD824, IM, or DMSO and found that the PDX mice with Ph- pre-B ALL cells (P\#1, $\mathrm{P} \# 2$, and $\mathrm{P} \# 3$ ) that were treated with GZD824 had significantly lower percentages of pre-B ALL cells in PB, SP, and BM than those from the IM or DMSO groups (Figure 4A-4D), despite the observation that the reduction of tumor load in the BM of xenografts from P\#3 is not significant in the GZD824 group compared to IM and DMSO groups. In contrast, GZD824 treatment reduced the number of circulating pre-B ALL cells in the $\mathrm{PB}$ of the $\mathrm{Ph}+$ pre-B ALL PDX mice but failed to reduce the residual pre-B ALL cells in SP or BM (Figure 4E-4G). IM did not significantly inhibit the growth of either $\mathrm{Ph}+$ or $\mathrm{Ph}$ - pre-B ALL cells in the PDX models (Figure 4A-4G). Taken together, these results show that GZD824 more effectively suppresses the growth of human Ph- pre-B ALL cells than that of $\mathrm{Ph}+$ pre-B ALL cells in vivo.

\section{GZD824 inhibits the SRC kinase in pre-B ALL cells}

To elucidate the mechanism of GZD824 inhibition for pre-B ALL cells, kinase assays were performed to determine possible binding targets of GZD824. Besides ABL kinases and phosphorylated ABL kinases, GZD824 bound to the SRC kinase with high affinity (Supplementary Table S2). The inhibition of the SRC/ STAT3 signal pathways causes cell-cycle arrest and apoptosis [22]. We thus determined that GZD824 treatment induces pre-B ALL cells to undergo apoptosis through the SRC/STAT3 pathway. We evaluated the effects of GZD824 on the SRC/STAT3 pathway in NALM6 cells by measuring the phosphorylation profiles of SRC and STAT3. As expected, GZD824 treatment reduced both phosphorylated SRC (Figure 5A) and phosphorylated
STAT3 in NALM6 cells (Figure 5B). We also found that GZD824 downregulated c-Myc oncogene expression and suppressed $\mathrm{Rb}$ phosphorylation (Figure 5C). Further evidence of GZD824 inhibition of SRC/STAT3 activity was derived by gene expression analysis of several STAT3 target genes. Treatment with GZD824 caused further downregulation of genes known to be positively regulated by STAT3, such as the anti-apoptotic gene BCL-XL [23], the positive cell cycle regulators $C C N D 1[24]$ and $C D K 4$ [25] and the negative cell cycle regulator CDKN1A [24] (Figure 5D).

To test whether STAT3 is the main target of the SRC signaling pathway in pre-B ALL, we treated NALM6 cells with GZD824, SRC inhibitor (KX2-391), STAT3 inhibitor (HO-3867), or DMSO. We found that KX2391 and HO-3867 induce similar amounts of apoptosis, demonstrating that STAT3 is the main target of the SRC signaling pathway in pre-B ALL (Figure 5E). In addition, GZD824 showed a significantly increased apoptotic level compared to KX2-391, HO-3867 and DMSO (Figure 5E). Accordingly, in addition to the SRC/STAT3 signaling pathway, other signaling pathways may be targeted by GZD824 inhibition.

\section{IGF-1 rescues GZD824 inhibition via the IRS1/ PI3K/AKT signaling pathway}

The percentages of residual pre-B ALL cells in $\mathrm{PB}, \mathrm{SP}$, and $\mathrm{BM}$ were different in individual PDX mice upon GZD824 treatment (Figure 4A-4G), suggesting that pre-B ALL cells in these compartments showed different resistance capacities to GZD824. Therefore, we compared the GZD824 sensitivity among the pre-B ALL cells harvested from the $\mathrm{PB}, \mathrm{SP}$, and $\mathrm{BM}$ of the same pre-B ALL PDX mice. Before in vitro assay, the pre-B ALL cells from different organs were purified with human anti-CD45+ by MACS (Supplementary Figure S3A-B). Interestingly, compared to the pre-B ALL cells derived from $\mathrm{PB}$ and SP, the percentages of apoptotic pre-B ALL cells derived from BM were significantly lower than those from SP and PB 24 hours after GZD824 treatment in vitro (Figure $6 \mathrm{~A}$ ), suggesting that the pre-B ALL cells from BM were more tolerant to GZD824 treatment. We previously found that insulin-like growth factor 1 (IGF-1), which is highly expressed in BM, increased the resistance capacity of pre-B ALL cells to chemotherapy via the PI3K/AKT pathway (Zhiwu Jang unpublished). Thus, we hypothesized that IGF-1 would rescue pre-B ALL cells from GZD824 inhibition by up-regulating the PI3K/AKT pathway. Primary pre-B ALL cells treated with GZD824 alone showed much higher apoptotic levels than those cells treated with both GZD824 and IGF-1 (Figure 6B), suggesting that IGF-1 decreased the sensitivity of pre-B ALL cells to GZD824 treatment.

$\mathrm{PI} 3 \mathrm{~K} / \mathrm{AKT}$ signaling is the major pathway controlled by IGF-1[26]. Binding of IGF-1 with IGF-1R induces 
A
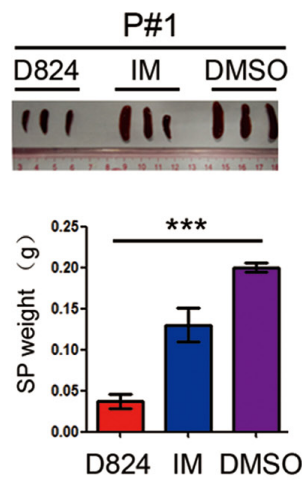

B
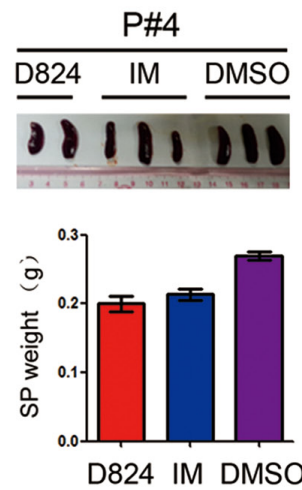
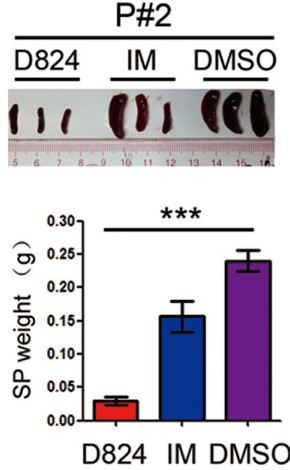

P\#3

D824 IM DMSO

(1) 110.89

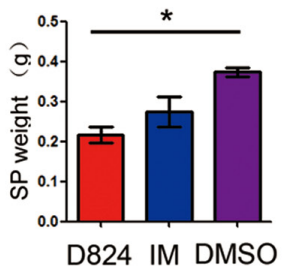

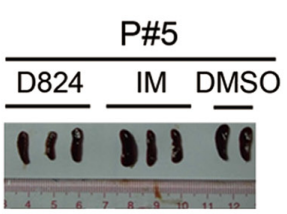

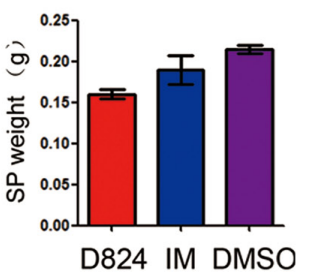

C

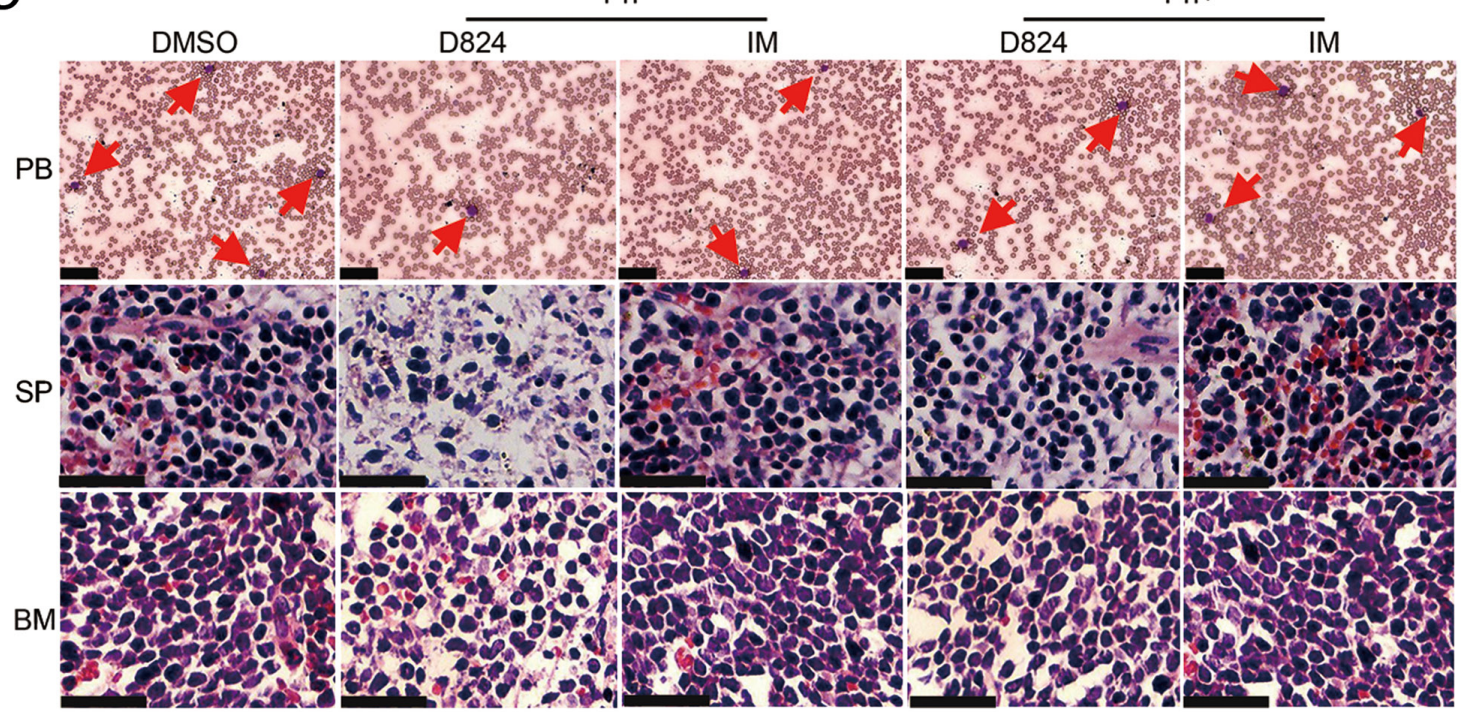

Figure 3: GZD824 inhibits the growth of pre-B ALL cells in PDX models. A. SP of the mice that were injected with pre-B ALL cells of P\#1, P\#2, and P\#3 with GZD824, imatinib (IM), or DMSO treatment were compared for sizes and weights. Top: The pictures of SP sizes were compared in GZD824, IM, or DMSO group. Bottom: Statistical analysis of SP weight in GZD824, IM or DMSO group B. SP of the mice that were injected with pre-B ALL cells of P\#4 and P\#5 with GZD824, IM, or DMSO treatment were compared for sizes and weights. Top: The pictures of SP sizes were compared in GZD824, IM or DMSO group. Bottom: Statistical analysis of SP weight in GZD824, IM or DMSO group. C. PDX mice of P\#2 with GZD824 treatment had reduced leukemic infiltration in PB, SP, and BM compared to the mice treated with IM or DMSO. Tissue sections of PB (top), SP (middle), and BM (bottom) were assessed histologically after Wright-Giemsa or H\&E staining. Red arrows represent examples of leukemic blasts. Slides were imaged on an Olympus BX46 microscope with an Olympus DP72 camera at $\times 40$ magnifications with 0.5 apertures; Olympus cellSens Standard 1.5 image acquisition software was used. Scale bar $=25 \mu \mathrm{m}$ in all photomicrographs. Data are shown as the mean \pm SEM (error bars) from three independent experiments. Significance values: ${ }^{*} \mathrm{P}<0.05 ;{ }^{* *} \mathrm{P}<0.01 ;{ }^{* * *} \mathrm{P}<0.001$. 
A

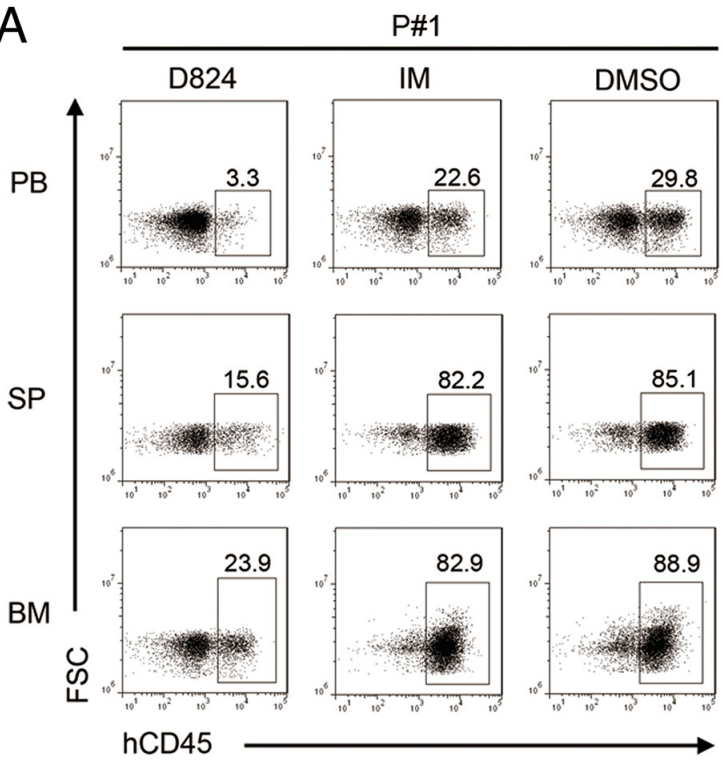

$\mathrm{D}$

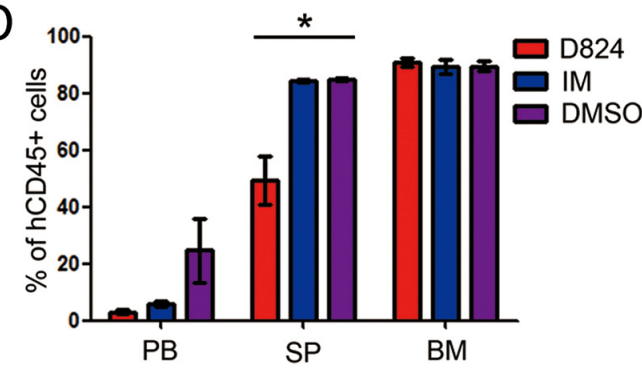

$\mathrm{F}$
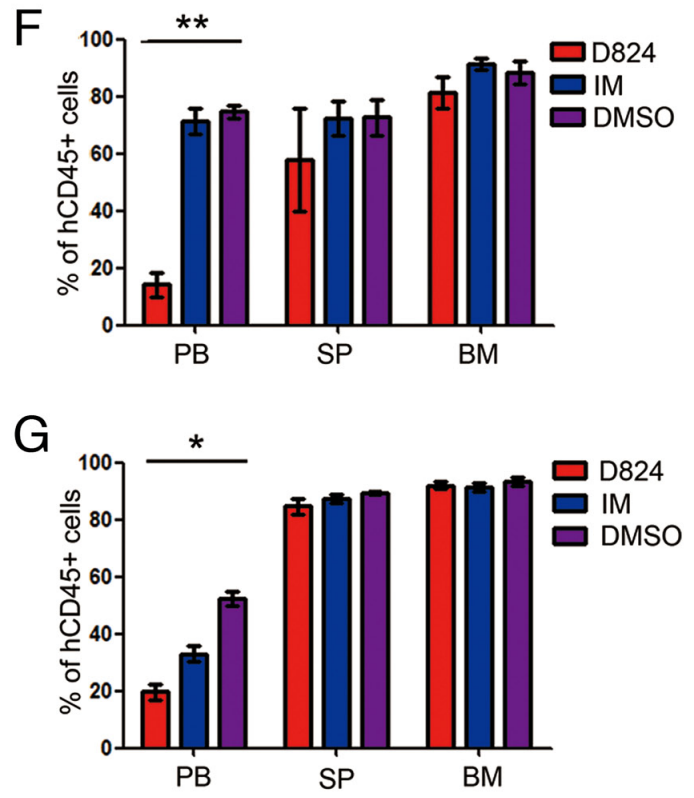
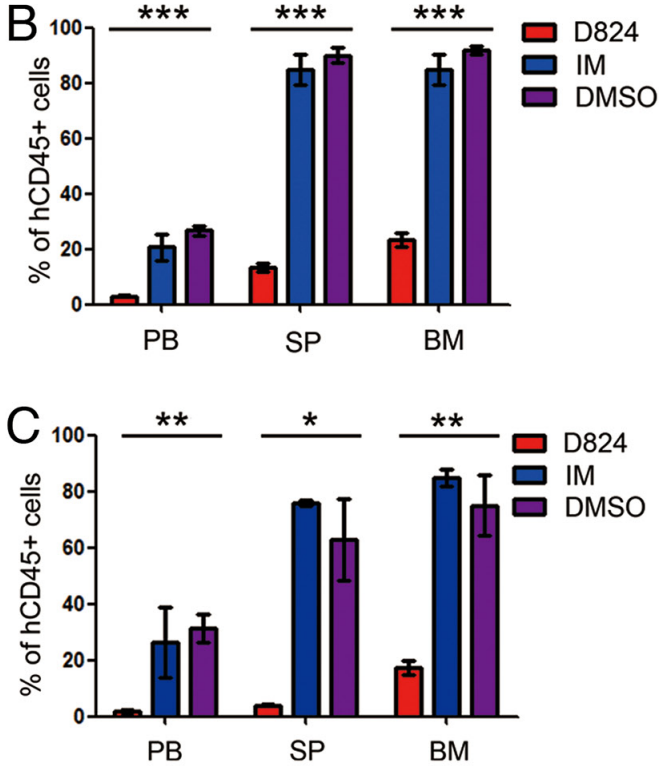

E
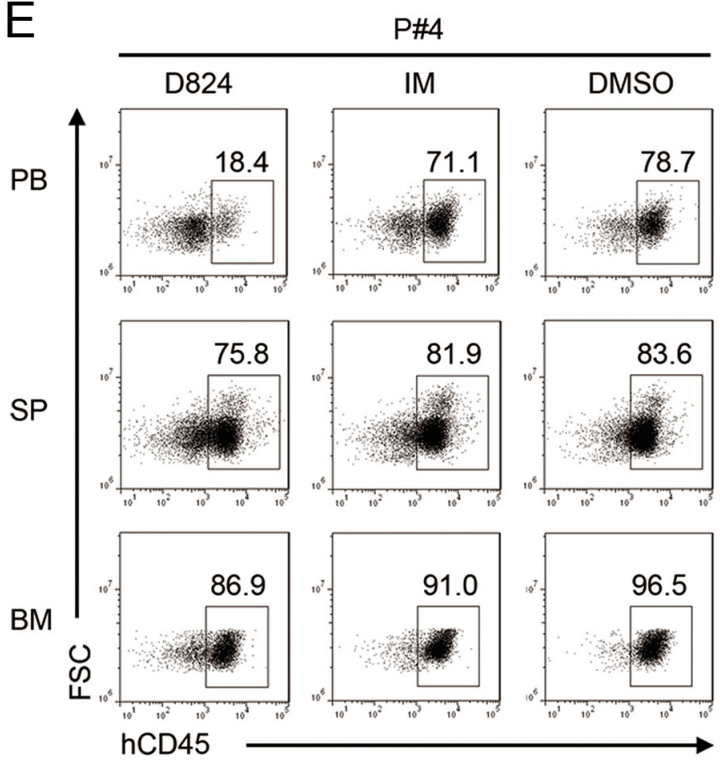

Figure 4: Effects of GZD824 on pre-B ALL cells engraftment. A. Representative flow cytometric analysis of human CD45+ cells in PB (top), SP (middle), and BM (bottom) of P\#1-engrafted mice after treatment with GZD824, IM, or DMSO. B-D. The percentages of human CD45+ cells in the PB, SP, and BM of mice transplanted with pre-B ALL cells of P\#1 (B), P\#2 (C), and P\#3 (D) treated under different conditions were measured when the mice were culled. E. Representative flow cytometric analysis of human CD45+ cells in PB (top), SP (middle), and BM (bottom) of P\#4-engrafted mice after treatment with GZD824, IM, or DMSO. F-G. The percentages of human $\mathrm{CD} 45+$ cells in the PB, SP, and BM of mice transplanted with pre-B ALL cells of P\#4 (F) or P\#5 (G) treated under different conditions were measured when the mice were culled. Significance values: ${ }^{*} \mathrm{P}<0.05 ;{ }^{* *} \mathrm{P}<0.01 ;{ }^{* * * *} \mathrm{P}<0.001$. 
tyrosine phosphorylation of insulin receptor substrate 1 (IRS1), which in turn activates PI3K and its downstream target, AKT $[27,28]$. Our observation that IGF-1 rescued the inhibition of pre-B ALL cells by GZD824 treatment led us to hypothesize that GZD824 would directly restrict IRS1 expression, which would result in a subsequent activation of AKT in pre-B ALL cells. To test this hypothesis, NALM6 cells were treated with GZD824, followed by analysis of the levels of proteins related to IGF-1 signaling and AKT phosphorylation. The levels of IRS1 protein and phosphorylated AKT (Ser473) were reduced in the GZD824-treated NALM6 cells (Figure 6C). Furthermore, the primary pre-B ALL cells with lower expression of IRS1 (Figure 4A-4G) were more sensitive to GZD824 treatment in xenografts (Supplementary Figure S4). Consistently, primary pre-B ALL cells treated with GZD824 resulted in a reduction in IRS1 and phosphorylated AKT (Ser473) (Figure 6D). As expected, IGF-1 significantly increased the levels of IRS 1 and phosphorylated AKT (Ser473) in primary pre-B ALL cells and reversed increases in IRS1 and phosphorylated AKT in primary pre-B ALL cells after treatment with GZD824 (Figure 6D). Collectively, these studies suggest that GZD824 negatively regulated the survival and proliferation of pre-B ALL cells by inhibiting the SRC kinase and PI3K/AKT signaling pathways (Figure 7).
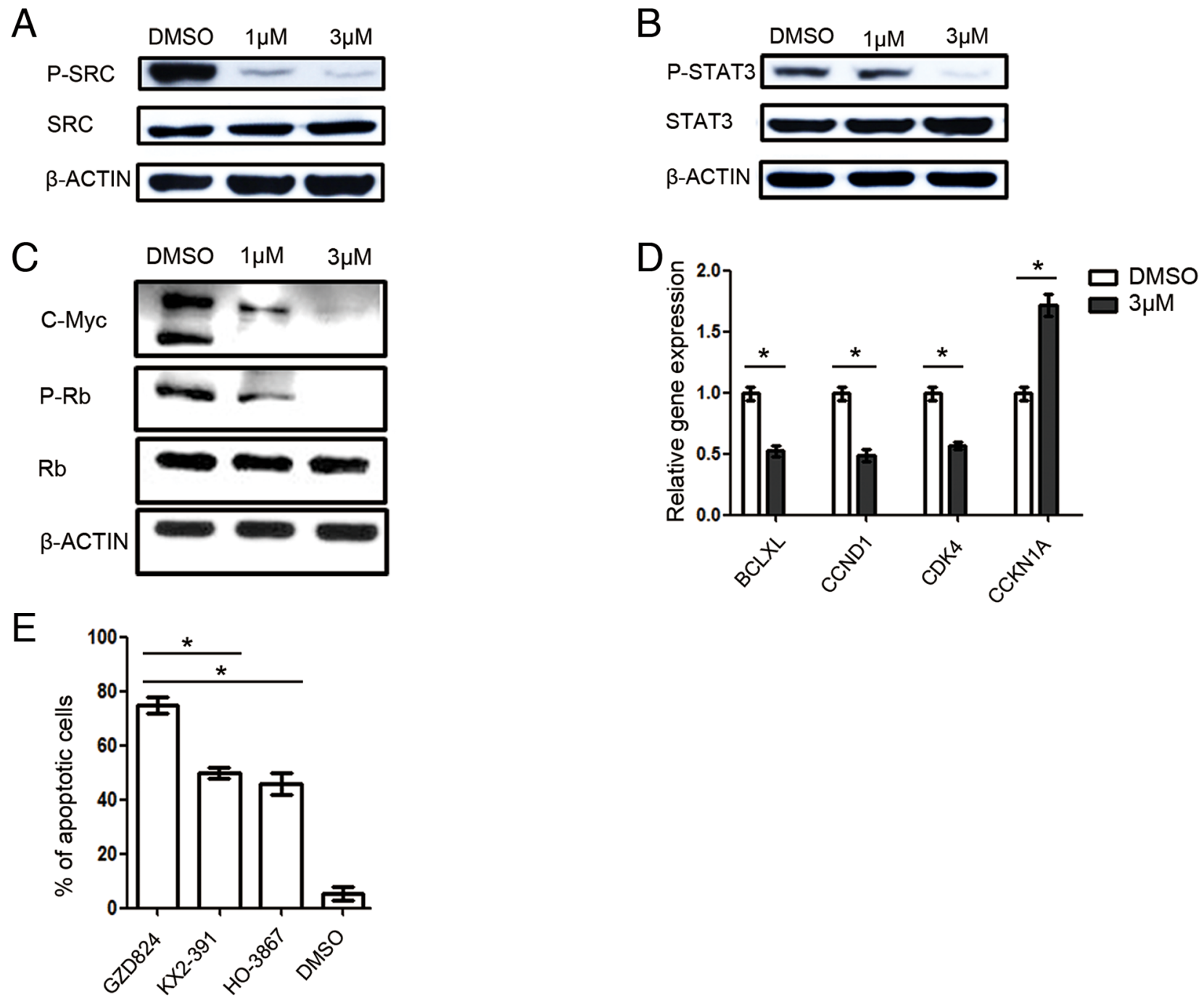

Figure 5: GZD824 inhibits the SRC kinase in pre-B ALL cells. A-C. Western blot analysis of D824-treated NALM6 cells. Cells were treated with DMSO, GZD824 $(1 \mu \mathrm{M})$, or GZD824 $(3 \mu \mathrm{M})$ for 24 hours. Lysates were analyzed with antibodies to (A) phospho-SRC and SRC; (B) phospho-STAT3 and STAT3; and (C) phospho-Rb, Rb, and C-Myc. D. qRT-PCR products of $B C L-X L, C C N D 1, C D K 4$, and CCKN1A mRNA were normalized to GAPDH and presented as fold increase or decrease compared to control, 24 hours after treatment with $3 \mu \mathrm{M}$ GZD824. E. NALM6 cells were treated with GZD824, SRC inhibitor (KX2-391), STAT3 inhibitor (HO-3867), or DMSO for 24 hours. Statistical analysis of Annexin V-positive cells in $3 \mu \mathrm{M}$ of drug treated NALM6 cells. All data from independent experiments are presented as mean \pm SEM. Significance values: ${ }^{*} \mathrm{P}<0.05 ;{ }^{* *} \mathrm{P}<0.01 ;{ }^{* * *} \mathrm{P}<0.001$. 

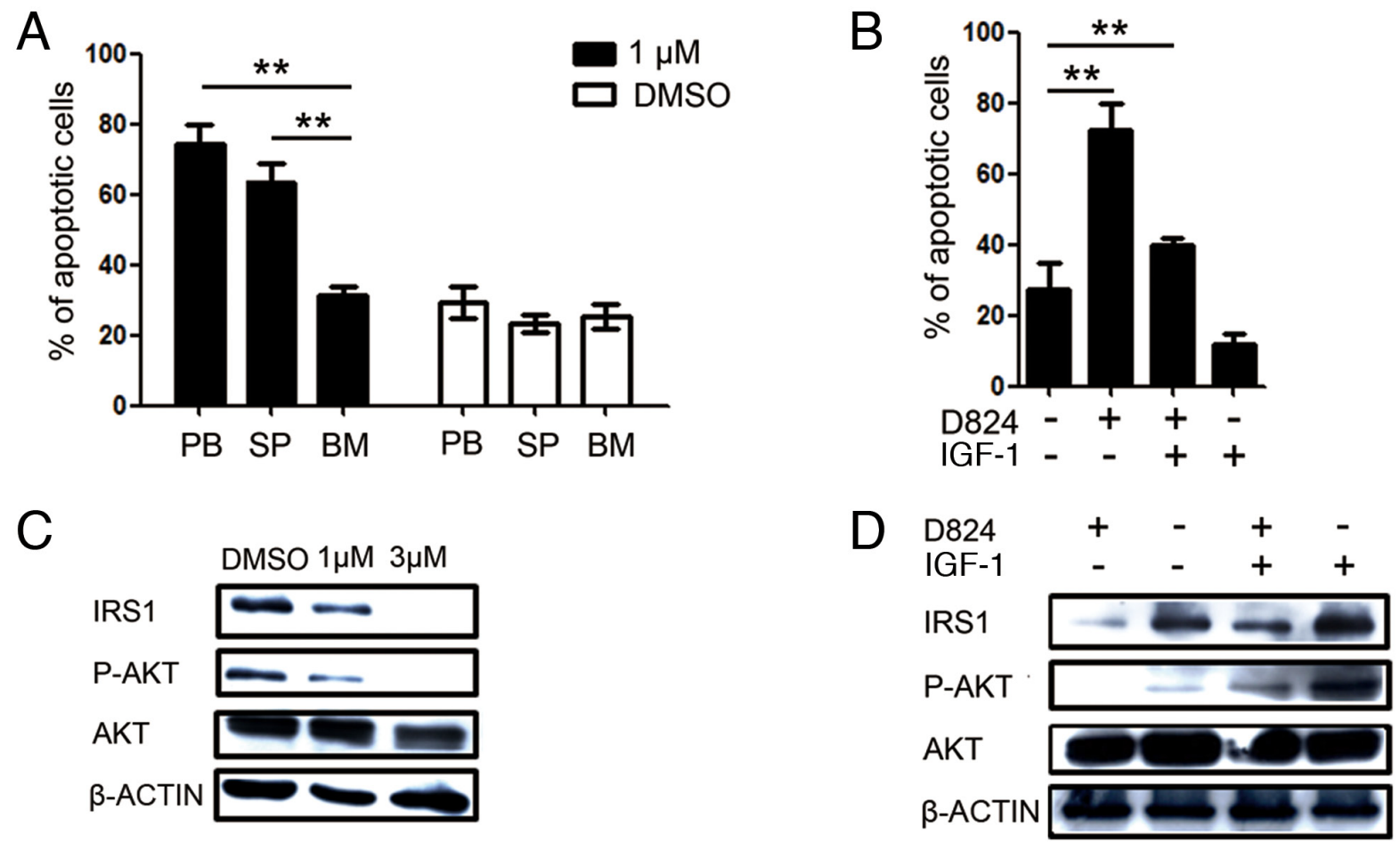

Figure 6: GZD824 inhibits PI3K/AKT signaling in pre-B ALL cells. A. Cells were harvested from PB, SP, and BM of P\#2 xenograft mice and cultured with or without $1 \mu \mathrm{M}$ GZD824 for $24 \mathrm{~h}$. Bars represent the mean percentages of AnnexinV+ cells in each group. B. Primary pre-B ALL cells from spleen of P\#1 xenograft mouse treated with DMSO, GZD824 (1 $\mu \mathrm{M})$, IGF-1 (10ng/ML), or both. Bars represent the mean percentages of AnnexinV+ cells in each group. C. Western blot analysis of NALM6 cells. Cells were treated with DMSO, GZD824 $(1 \mu \mathrm{M})$, or GZD824 $(3 \mu \mathrm{M})$ for 24 hours. Lysates were analyzed with antibodies against IRS1, phosphate AKT, and AKT. D. Western blot analysis of primary pre-B ALL cells. Primary cells treated with GZD824 (1 $\mu$ M), IGF-1 (10ng/ML), or both for 24 hours. Lysates were analyzed with antibodies against Irs1, phosphate AKT, and AKT.

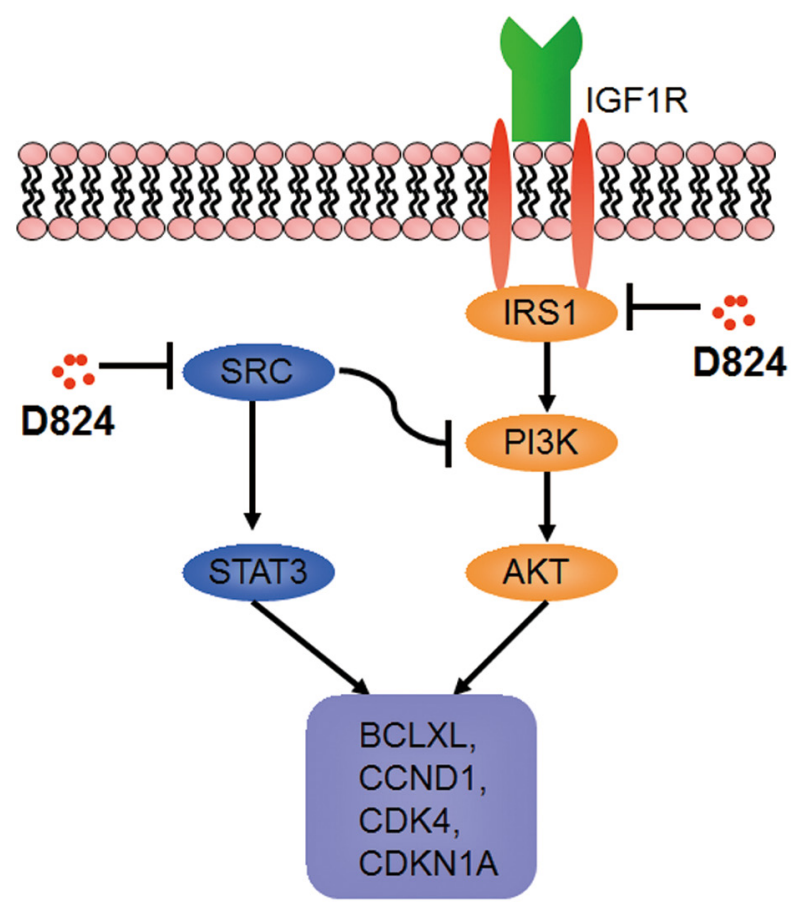

Figure 7: A proposed mechanism for the anticancer activity of GZD824. A detailed description of the mechanism can be found in the results and discussion sections. 


\section{DISCUSSION}

We previously showed that GZD824 suppresses $\mathrm{Ph}+\mathrm{CML}$ cells and induces tumor regression in mouse xenograft tumor models by inhibiting BCR-ABL kinase $[16,17]$. Here we found that GZD824 treatment significantly decreased proliferation of both human $\mathrm{Ph}+$ and $\mathrm{Ph}-$ pre-B ALL cells, indicating that GZD824's anti-tumor activity in pre-B ALL is partly independent of BCR-ABL kinase activity. Abnormal interactions between BCR-ABL leads to activation of BCR-ABL tyrosine kinase, SRC kinases, the PI3K pathway, Rasmitogen-activated protein kinase (Ras/MAPK), and the Janus-activated kinase (JAK) pathway [29, 30]. SRC kinases remain active after IM treatment in $\mathrm{Ph}+$ leukemia [31]. Although GZD824 does not bind to JAK or MAPK, as revealed in the present kinase assay results, MAPK or JAK might still be activated in GZD824-treated pre-B ALL cells. This may explain the relatively poor activity of IM and GZD824 against Ph+ pre-B ALL. Moreover, it is therefore possible to efficiently eradicate $\mathrm{Ph}+$ pre- $\mathrm{B}$ ALL cells by combining multiple TKIs that target these pathways.

$\mathrm{Ph}$ - pre-B ALL cells were more sensitive to GZD824 than $\mathrm{Ph}+$ pre-B ALL cells both in vitro and in vivo, suggesting that other mechanisms are involved in the action of GZD824 inhibition of pre-B ALL. Levels of both P-SRC and P-STAT3, a downstream phosphorylation target of SRC, were significantly reduced after treatment with GZD824 in $\mathrm{Ph}-$ pre-B ALL cells (Figure 7). GZD824 suppressed both SRC and PI3K/AKT in $\mathrm{Ph}-$ cells, which is consistent with other reports that inhibition of SRC kinase or PI3K/AKT signaling suppresses ALL cells in vitro and in vivo [11,32-34]. To our knowledge, GZD824 is the first compound to show an antitumor effect in pre-B ALL by inhibiting both the SRC kinase and IRS1/PI3K/AKT pathways (Figure 7). IRS1 is an important mediator between IGF-1 receptors and the PI3K/AKT pathway [35, 36]. An earlier study suggested that IRS1 expression correlates negatively with survival in patients with $\mathrm{Ph}+\mathrm{ALL}$ [37]. In the present study, levels of IRS1 expression were negatively correlated with GZD824 treatment outcomes in xenografts (Supplementary Figure S4). Thus IRS 1 could potentially be used as a biomarker to predict GZD824 efficiency in treating pre-B ALL in the future.

In sum, our findings indicate GZD824 is cytotoxic to pre-B ALL cell lines and primary cells in vitro and in xenografts. Moreover, GZD824 specifically inhibits SRC kinase and PI3K/AKT, making it a highly promising agent for clinical testing for the treatment of acute pre-B ALL.

\section{MATERIALS AND METHODS}

\section{GZD824 compound and other chemicals}

GZD824 was synthesized in Ke Ding's laboratory. Compound solutions were freshly prepared by dissolving the compounds in dimethyl sulfoxide (DMSO) (D2650, Sigma Aldrich, St. Louis, MO, USA) before each experiment. IM (SML1027, Sigma Aldrich, St. Louis, MO, USA) was purchased from Sigma Aldrich.

\section{Cell culture}

Human pre-B ALL cell lines NALM6 and SUPB15 were purchased from American Type Culture Collection (ATCC, Maryland, USA). All pre-B ALL cell lines were maintained in cell culture media and conditions as recommended by the ATCC. Cells were treated with GZD824 for 24 hours. GZD824 $(3 \mu \mathrm{M}$, $1 \mu \mathrm{M}$, or $0.5 \mu \mathrm{M})$ was used in the experiments unless otherwise noted. NALM6 and SUPB15 cells were maintained in RPMI-1640 medium (Gibco, New York, NY, USA) with $10 \%$ fetal bovine serum (Biochrom, Melbourne, Australia).

Human pre-B ALL cells were obtained from spleen (SP) of sick pre-B ALL xenograft mice. Human CD45+ pre-B ALL cells, accounting for over $95 \%$ of the total SP mononuclear cells, were subjected in vitro assay. To determine the in vitro anticancer efficacy of GZD824, the drug was applied to fresh splenic pre-B ALL cells that were directly isolated from sick pre-B ALL xenograft mice in 3 independent experiments. In addition, fresh splenic cells were analyzed 24 hours post drug treatment. At this time point about $20 \%$ of the total cells in the vehicle group are apoptotic. We did not add any cytokine cocktails during the drug efficacy test. All cells were cultured at $37^{\circ} \mathrm{C}$ in $5 \%$ carbon dioxide and a normal level of oxygen.

\section{Isolation of human pre-B ALL cells}

All pre-B ALL samples were obtained from the Nanfang Hospital, Southern Medical University. For all of the patients who participated in this study, written informed consent was obtained, which was approved by the Ethics Committee of Guangzhou Institutes of Biomedicine and Health, Chinese Academy of Sciences. Human pre-B ALL cells were isolated with Lymphoprep (StemCell Technologies, Canada) according to the manufacturer's instructions.

\section{Proliferation assays}

Cells were seeded at a density of $0.5 \times 10^{6}$ to $1 \times 10^{6}$ cells per $\mathrm{ml}$ in the presence or absence of inhibitor for the 
indicated times. Cell proliferation was measured 24 hours after treatment, using the Cell Counting Kit-8 assay (CCK-8, DOJINDO, Kumamoto, Japan). The proliferation analysis of each group in each individual experiment and throughout the whole experimental process was performed in triplicate.

\section{Cell-cycle analysis and detection of apoptotic cells}

Cell cycle analysis was performed by flow cytometry after propidium iodide (PI) staining as described $[14,15]$. Approximately $2 \times 10^{6}$ cells were suspended in $0.5 \mathrm{ml}$ of phosphate-buffered saline (PBS) and vortexed with $3 \mathrm{ml}$ of $80 \%$ ethanol. Cells were fixed at $4^{\circ} \mathrm{C}$ for $1 \mathrm{hr}$, washed with PBS, re-suspended in PBS, and vortexed vigorously. Cells were re-suspended in 1 $\mathrm{ml}$ of PBS containing $50 \mu \mathrm{g} / \mathrm{ml}$ of DNase-free RNase A (EN0531, Thermo Fisher scientific, Waltham, USA) and $50 \mu \mathrm{g} / \mathrm{ml}$ of propidium iodide PI (P4170, Sigma Aldrich, St. Louis, MO, USA). Cells were stained for at least $1 \mathrm{hr}$ at room temperature in the dark. Stained cells were then subjected to flow cytometric analysis by an Accuri ${ }^{\mathrm{TM}} \mathrm{C6}$ (BD Biosciences, CA, USA).

For identification of apoptotic cells among NALM6, SUPB15, and primary pre-B ALL cells, the GZD824-treated cells were stained with Annexin V Apoptosis Detection Kit (88-8007, BD ebioscience, CA, USA) according to the manufacturer's instructions (Affymetrix ebioscience, CA, USA) and then subjected to flow cytometric analysis by the Accuri' ${ }^{\mathrm{TM}}$ C6 (BD Biosciences, CA, USA). For the in vitro drug sensitivity test in Figure 6A, the human CD45+ cells in spleen and bone marrow from sick mice account for over $95 \%$ of the total. We enriched human CD $45+$ cells in PB by MACS according to the manufacturer's instruction. After the enrichment, the purity of human CD45+ cell in $\mathrm{PB}$ reached $95 \%$. The percentage of apoptotic cells was demarcated as the amount of both early and late facets of apoptosis (annexin V positive), as previously described [16]. All data were analyzed with FlowJo software (Tree Star, Inc., Ashland, USA).

\section{H\&E staining}

Peripheral blood (PB), spleen (SP), and bone marrow (BM) from mice sacrificed by $\mathrm{CO}_{2}$ asphyxiation were dissected and paraffin embedded for histological staining. All protocols used in this study were approved by the animal protocol committee of the Guangzhou Institutes of Biomedicine and Health (GIBH).

\section{Active-site-dependent competition kinase binding assay}

Kinase assay was performed as previously described $[12,17]$. The binding activities of GZD824 were analyzed by KINOME scan system conducted by Ambit Bioscience
(CA, USA). Briefly, kinases were tagged with DNA. The ligands were biotinylated and immobilized to streptavidin coated beads. The binding reactions were assembled by incubating DNA-tagged kinases, immobilized ligands, and test compounds in binding reactions $(20 \%$ SeaBlock, $0.17 \times$ PBS, $0.05 \%$ tween-20, $6 \mathrm{mM}$ DTT) for $1.0 \mathrm{~h}$ at room temperature. The affinity beads were washed with washing buffer $(1 \times$ PBS, $0.05 \%$ Tween-20) first and then elution buffer $(1 \times$ PBS, $0.05 \%$ Tween $20,0.5 \mu \mathrm{M}$ nonbiotinylated affinity ligands). The kinase concentration in the eluate was determined by quantitative PCR of the DNA tagged to the kinase. The ability of the test compound to bind to the kinase was evaluated with percent control (\%) as (test compound signal - positive control signal)/negative control signal-positive control signal) $\times 100 \%$. Negative control is DMSO control $(100 \% \mathrm{ctrl})$ and positive control is control compound $(0 \% \mathrm{ctrl})$.

\section{Western blot analysis}

For Western blot analysis, $30 \mu \mathrm{g}$ of total protein extracts prepared from NALM6 or primary pre-B ALL cells from SP of PDX mice were separated on SDS-PAGE and transferred to a PVDF membrane (Bio-Rad, Hercules, CA, USA). The following commercially available antibodies and dilutions were used for Western blotting: human anti-STAT3 (ab119352, Abcam, UK), human antiphospho-STAT3 (Y705) (ab76315, Abcam, UK), human anti-SRC (ab32102, Abcam, UK), human anti-phosphoSRC (Y419) (ab185617, Abcam, UK), human anti-RB (9313, Cell Signaling Technology, MA, USA), human anti-phospho-RB (Ser807/811) (8516, Cell Signaling Technology, MA, USA), human anti-C-myc (13987, Cell Signaling Technology, MA, USA), anti-AKT (pan) (4691P, Cell Signaling Technology, MA, USA), anti-phosphoAKT (Ser473) (4060P, Cell Signaling Technology, MA, USA), anti-IRS-1 (2390S, Cell Signaling Technology, MA, USA), and human anti- $\beta$-actin (4970, Cell Signaling Technology, MA, USA). Western blot analysis was performed with cell lines or primary pre-B ALL cells from SP following GZD824 treatment, and signal intensities were normalized to $\beta$-actin signals.

\section{Transplantation experiments}

Animal experiments were performed in the Laboratory Animal Center of GIBH, and all animal procedures were approved by the Animal Welfare Committee of GIBH. All protocols were approved by the relevant institutional animal care and use committee (IACUC). Bone marrow samples were acquired at diagnosis from pre-B ALL patients. Leukemia blasts were enriched by Ficoll-Paque centrifugation and were washed, precipitated, and pelleted in PBS. Then, Leukemia blasts were enriched for human CD45+ cells by MACS according to the manufacture instruction. Freshly isolated primary CD45+ cells were transplanted into NODSCID- 
IL2RG-/- (NSI) mice to establish P1 PDX mice. P1 PDX mice were established by intravenously engrafting $2 \times 10^{6}$ CD45+ cells into 8-week-old, sub-lethally irradiated NSI mice. P2 to Pn $(n<5)$ PDX mice were established by intravenously injecting $1 \times 10^{6}$ splenic pre-B ALL cells from sick pre-B ALL xenograft mice into 8-week-old, sub-lethally irradiated NSI mice. The hCD45+ pre-B ALL cells in the sick PDX mouse, which account for over $95 \%$ of the total, were used for further transplantation. Freshly isolated splenic pre-B ALL cells were transplanted into NSI mice. Cell viability, as determined by trypan blue exclusion staining, was typically $>90 \%$. If the viability of cells was less than $80 \%$, dead cells were eliminated using a "dead cell removal kit" (Miltenyi Biotec Inc., Germany).

Compound treatment started when the percentage of pre-B ALL cells in PB of xenograft mice reached $1 \pm$ $0.2 \%$. To remove the red blood cells, the PB and SP were treated with $1 \times$ RBC Lysis Buffer (eBioscience) according to the manufacturer's instructions. The peripheral blood mononuclear cells (PBMCs) were analyzed by human anti-CD45 antibody and analyzed with an Accuri C6 (BD bioscience). Mice injected with tumor cells were randomly divided into three groups: the control group, treated with DMSO; the IM group, treated with IM $(50 \mathrm{mg} / \mathrm{kg}$ body weight) dissolved in PBS; and the GZD824 treatment group, treated with GZD824 (25 mg/kg body weight) dissolved in DMSO solution. Mice received DMSO, IM $(50 \mathrm{mg} / \mathrm{kg})$, or GZD824 $(25 \mathrm{mg} / \mathrm{kg})$ by intragastric administration daily for two weeks.

\section{Flow cytometry analysis}

Cells were isolated from PB, BM, and SP for flow cytometric analyses. For analysis, the human pre-B ALL cells were labeled with anti-hCD45-PE. The antibody was obtained from eBioscience (San Diego, CA, USA) unless specifically stated. Flow cytometric analysis was performed using an Accuri ${ }^{\mathrm{TM}}$ C6 or FACSAria ${ }^{\mathrm{TM}}$ II (BD Biosciences, CA, USA). All data were analyzed with FlowJo software (Tree Star, Inc., Ashland, USA).

\section{qRT-PCR}

RNA was extracted using TRIzol reagent (15596026, Invitrogen, Grand Island, NY, USA), according to the manufacturer's recommended protocol. qRT-PCR was performed using Applied Biosystems StepOne and StepOne Plus Real-Time PCR Systems (Foster City, CA, USA). The experiments were repeated a minimum of three times to confirm the results.

\section{Statistical analyses}

Data were analyzed with the Student $t$-test using GraphPad Prism 5 software. P values of less than 0.05 were considered statistically significant.

\section{ACKNOWLEDGMENTS}

This study was supported by the Strategic Priority Research Program of the Chinese Academy of Sciences (Grant No.: XDA01020310), the National Natural Science Foundation of China (Grant No.: 81272329, 81522002, and 81327801), the Natural Science Fund for Distinguished Young Scholars of Guangdong Province (Grant No.: 2014A030306028), the Guangdong Provincial Outstanding Young Scholars Award (Grant No.: 2014TQ01R068), the Guangdong Provincial Basic Research Program (Grant No.: 2015B020227003), the Guangdong Provincial Research and Commercialization Program (Grant No.: 2014B090901044), the Guangdong Province and Chinese Academy of Sciences Joint Program for Research and Commercialization Program (Grant No.: 2013B091000010), the Guangzhou Basic Research Program (Grant No.: 201510010186), the MOST funding of the State Key Laboratory of Respiratory Disease, and the National Basic Research Program of China (973 Program) (2011CB504004 and 2010CB945500).

\section{CONFLICTS OF INTEREST}

The authors declare no competing financial interests.

\section{REFERENCES}

1. Zhou Y, You MJ, Young KH, Lin P, Lu G, Medeiros LJ, Bueso-Ramos CE. Advances in the molecular pathobiology of B-lymphoblastic leukemia. Human pathology. 2012; 43:1347-1362.

2. Moorman AV. The clinical relevance of chromosomal and genomic abnormalities in B-cell precursor acute lymphoblastic leukaemia. Blood Rev. 2012; 26:123-135.

3. De Braekeleer E, Basinko A, Douet-Guilbert N, Morel F, Le Bris MJ, Berthou C, Morice P, Ferec C, De Braekeleer M. Cytogenetics in pre-B and B-cell acute lymphoblastic leukemia: a study of 208 patients diagnosed between 1981 and 2008. Cancer Genet Cytogen. 2010; 200:8-15.

4. Tallen G, Ratei R, Mann G, Kaspers G, Niggli F, Karachunsky A, Ebell W, Escherich G, Schrappe M, Klingebiel T, Fengler R, Henze G, von Stackelberg A. Long-term outcome in children with relapsed acute lymphoblastic leukemia after time-point and site-ofrelapse stratification and intensified short-course multidrug chemotherapy: results of trial ALL-REZ BFM 90. Journal of clinical oncology. 2010; 28:2339-2347.

5. Armstrong GT, Sklar CA, Hudson MM, Robison LL. Long-term health status among survivors of childhood cancer: does sex matter? Journal of clinical oncology. 2007; 25:4477-4489. 
6. Goldman JM, Melo JV. Chronic myeloid leukemia-advances in biology and new approaches to treatment. The New England journal of medicine. 2003; 349:1451-1464.

7. Drugs of choice for cancer. Treatment guidelines from the Medical Letter. 2003; 1:41-52.

8. Xi S, Zhang Q, Dyer KF, Lerner EC, Smithgall TE, Gooding WE, Kamens J, Grandis JR. Src kinases mediate STAT growth pathways in squamous cell carcinoma of the head and neck. The Journal of biological chemistry. 2003; 278:31574-31583.

9. Kharas MG, Okabe R, Ganis JJ, Gozo M, Khandan T, Paktinat M, Gilliland DG, Gritsman K. Constitutively active AKT depletes hematopoietic stem cells and induces leukemia in mice. Blood. 2010; 115:1406-1415.

10. Vivanco I, Sawyers CL. The phosphatidylinositol 3-Kinase AKT pathway in human cancer. Nature reviews Cancer. 2002; 2:489-501.

11. Wong J, Welschinger R, Hewson J, Bradstock KF, Bendall LJ. Efficacy of dual PI-3K and mTOR inhibitors in vitro and in vivo in acute lymphoblastic leukemia. Oncotarget. 2014; 5:10460-10472. https://doi.org/10.18632/oncotarget.2260.

12. Ren X, Pan X, Zhang Z, Wang D, Lu X, Li Y, Wen D, Long H, Luo J, Feng Y, Zhuang X, Zhang F, Liu J, et al. Identification of GZD824 as an orally bioavailable inhibitor that targets phosphorylated and nonphosphorylated breakpoint cluster region-Abelson (Bcr-Abl) kinase and overcomes clinically acquired mutation-induced resistance against imatinib. Journal of medicinal chemistry. 2013; 56:879-894.

13. Wang DP, Zhang Z, Lu XY, Feng YB, Luo K, Gan JR, Liu YX, Wan JT, Li XA, Zhang FX, Tu ZC, Cai QA, Ren XM, et al. Hybrid compounds as new Bcr/Abl inhibitors. Bioorg Med Chem Lett. 2011; 21:1965-1968.

14. Robles-Escajeda E, Lerma D, Nyakeriga AM, Ross JA, Kirken RA, Aguilera RJ, Varela-Ramirez A. Searching in mother nature for anti-cancer activity: anti-proliferative and pro-apoptotic effect elicited by green barley on leukemia/lymphoma cells. PloS one. 2013; 8:e73508.

15. Mori T, Hayashi T, Hayashi E, Su TP. Sigma-1 Receptor Chaperone at the ER-Mitochondrion Interface Mediates the Mitochondrion-ER-Nucleus Signaling for Cellular Survival. PloS one. 2013; 8.

16. Robles-Escajeda E, Das U, Ortega NM, Parra K, Francia G, Dimmock JR, Varela-Ramirez A, Aguilera RJ. A novel curcumin-like dienone induces apoptosis in triple-negative breast cancer cells. Cellular oncology. 2016.

17. Fabian MA, Biggs WH 3rd, Treiber DK, Atteridge CE, Azimioara MD, Benedetti MG, Carter TA, Ciceri P, Edeen PT, Floyd M, Ford JM, Galvin M, Gerlach JL, et al. A small molecule-kinase interaction map for clinical kinase inhibitors. Nature biotechnology. 2005; 23:329-336.

18. Xiao Y, Jiang Z, Li Y, Ye W, Jia B, Zhang M, Xu Y, Wu D, Lai L, Chen Y, Chang Y, Huang X, Liu H, et al. ANGPTL7 regulates the expansion and repopulation of human hematopoietic stem and progenitor cells. Haematologica. 2015; 100:585-594.

19. Xiao Y, Wei X, Jiang Z, Wang X, Ye W, Liu X, Zhang M, Xu Y, Wu D, Lai L, Yao H, Liu Z, Cao S, et al. Loss of Angiopoietin-like 7 diminishes the regeneration capacity of hematopoietic stem and progenitor cells. Journal of hematology \& oncology. 2015; 8:7.

20. Ye W, Jiang Z, Li GX, Xiao Y, Lin S, Lai Y, Wang S, Li B, Jia B, Li Y, Huang ZL, Li J, Feng F, et al. Quantitative evaluation of the immunodeficiency of a mouse strain by tumor engraftments. Journal of hematology \& oncology. 2015; 8:59.

21. Li W, Jiang Z, Li T, Wei X, Zheng Y, Wu D, Yang L, Chen $\mathrm{S}, \mathrm{Xu} \mathrm{B}$, Zhong M, Jiang J, Hu Y, Su H, et al. Genome-wide analyses identify KLF4 as an important negative regulator in T-cell acute lymphoblastic leukemia through directly inhibiting T-cell associated genes. Molecular cancer. 2015; $14: 26$.

22. Johnson FM, Saigal B, Talpaz M, Donato NJ. Dasatinib (BMS-354825) tyrosine kinase inhibitor suppresses invasion and induces cell cycle arrest and apoptosis of head and neck squamous cell carcinoma and non-small cell lung cancer cells. Clinical cancer research. 2005; 11:6924-6932.

23. Sethi G, Chatterjee S, Rajendran P, Li F, Shanmugam MK, Wong KF, Kumar AP, Senapati P, Behera AK, Hui KM, Basha J, Natesh N, Luk JM, et al. Inhibition of STAT3 dimerization and acetylation by garcinol suppresses the growth of human hepatocellular carcinoma in vitro and in vivo. Molecular cancer. 2014; 13:66.

24. Kamran MZ, Patil P, Gude RP. Role of STAT3 in cancer metastasis and translational advances. BioMed research international. 2013; 2013:421821.

25. Jo DH, Kim JH, Cho CS, Cho YL, Jun HO, Yu YS, Min JK, Kim JH. STAT3 inhibition suppresses proliferation of retinoblastoma through down-regulation of positive feedback loop of STAT3/miR-17-92 clusters. Oncotarget. 2014; 5:11513-11525. https://doi.org/10.18632/oncotarget.2546.

26. Walker MP, Diaugustine RP, Zeringue E, Bunger MK, Schmitt M, Archer TK, Richards RG. An IGF1/insulin receptor substrate-1 pathway stimulates a mitotic kinase $(\mathrm{cdk} 1)$ in the uterine epithelium during the proliferative response to estradiol. The Journal of endocrinology. 2010; 207:225-235.

27. Myers MG, Sun XJ, Cheatham B, Jachna BR, Glasheen EM, Backer JM, White MF. Irs-1 Is a Common Element in Insulin and Insulin-Like Growth Factor-I Signaling to the Phosphatidylinositol 3'-Kinase. Endocrinology. 1993; 132:1421-1430.

28. Suman S, Kallakury BVS, Fornace AJ, Datta K. Protracted Upregulation of Leptin and IGF1 is Associated with Activation of PI3K/Akt and JAK2 Pathway in Mouse Intestine after Ionizing Radiation Exposure. Int J Biol Sci. 2015; 11:274-283.

29. Melo JV, Deininger MW. Biology of chronic myelogenous leukemia--signaling pathways of initiation and 
transformation. Hematology/oncology clinics of North America. 2004; 18:545-568, vii-viii.

30. Ren R. Mechanisms of BCR-ABL in the pathogenesis of chronic myelogenous leukaemia. Nature reviews Cancer. 2005; 5:172-183.

31. Hu Y, Swerdlow S, Duffy TM, Weinmann R, Lee FY, Li S. Targeting multiple kinase pathways in leukemic progenitors and stem cells is essential for improved treatment of $\mathrm{Ph}+$ leukemia in mice. Proceedings of the National Academy of Sciences of the United States of America. 2006; 103:16870-16875.

32. Deininger M. Src kinases in $\mathrm{Ph}+$ lymphoblastic leukemia. Nature genetics. 2004; 36:440-441.

33. Buchner M, Fuchs S, Prinz G, Pfeifer D, Bartholome K, Burger M, Chevalier N, Vallat L, Timmer J, Gribben JG, Jumaa H, Veelken H, Dierks C, et al. Spleen Tyrosine Kinase Is Overexpressed and Represents a Potential Therapeutic Target in Chronic Lymphocytic Leukemia. Cancer research. 2009; 69:5424-5432.

34. Brandts CH, Sargin B, Rode M, Biermann C, Lindtner B, Schwable J, Buerger H, Muller-Tidow C, Choudhary C,
McMahon M, Berdel WE, Serve H. Constitutive activation of Akt by Flt3 internal tandem duplications is necessary for increased survival, proliferation, and myeloid transformation. Cancer research. 2005; 65:9643-9650.

35. Sun XJ, Rothenberg P, Kahn CR, Backer JM, Araki E, Wilden PA, Cahill DA, Goldstein BJ, White MF. Structure of the insulin receptor substrate IRS-1 defines a unique signal transduction protein. Nature. 1991; 352:73-77.

36. Hadari YR, Tzahar E, Nadiv O, Rothenberg P, Roberts CT Jr, LeRoith D, Yarden Y, Zick Y. Insulin and insulinomimetic agents induce activation of phosphatidylinositol 3'-kinase upon its association with pp185 (IRS-1) in intact rat livers. The Journal of biological chemistry. 1992; 267:17483-17486.

37. Juric D, Lacayo NJ, Ramsey MC, Racevskis J, Wiernik PH, Rowe JM, Goldstone AH, O’Dwyer PJ, Paietta E, Sikic BI. Differential gene expression patterns and interaction networks in BCR-ABL-positive and -negative adult acute lymphoblastic leukemias. Journal of clinical oncology. 2007; 25:1341-1349. 